\section{Molecular Identification of Japanese Barberry (Berberis thunbergii) Cultivars Using Amplified Fragment Length Polymorphism}

\author{
Marie-José Côté ${ }^{1}$ and Lisa Leduc \\ Ottawa Laboratory Fallowfield, Canadian Food Inspection Agency, 3851 \\ Fallowfield Road, Ottawa, Ontario, Canada K2H 8 P9
}

Additional index words. DNA, fingerprinting, ornamental shrub, PCR, Puccina graminis, wheat rust

\begin{abstract}
Plants of the genus Berberis have been forbidden entry in Canada because common barberry (Berberis vulgaris) is an alternate host for black stem rust of wheat. Japanese barberry (Berberis thunbergii), an ornamental shrub appreciated for its hardiness and attractiveness, is generally considered immune to rust. Therefore, the Canadian government has established a program allowing importation of 11 approved Japanese barberry cultivars. The success of the program relies on the proper identification of the approved varieties, which may not always be possible when the plant is dormant or missing some essential morphologic criteria. Therefore, a cultivar verification method has been established using the amplified fragment length polymorphism (AFLP) genotyping technique. The method was validated using DNA extracted from 41 plants sampled across the country and representing 23 Japanese barberry cultivars and representative of the 11 approved cultivars. The method successfully differentiated and confirmed the identity of all approved cultivars. Furthermore, the method was able to detect and identify two of six samples submitted for cultivar verification as mislabeled by the exporter because the AFLP patterns generated did not correspond to their reference cultivar patterns.
\end{abstract}

Common barberry (Berberis vulgaris L.) is an alternate host for black stem rust of wheat, Puccinia graminis Pers. The shrub provides a means for the pathogen to reproduce after the winter and then spread to new cereal plants in the spring (Clark et al., 1986; Pierce, 1981). Wheat rust is a destructive fungal disease of cereals and grasses capable of causing major crop losses (Pierce, 1981; Roelfs, 1982). The rust multiplies on barberry and often develops new and more virulent races to which cultivars of cereal crops may have little or no resistance (Clark et al., 1986; Pierce, 1981; Roelfs, 1982). To control the emergence of black stem rust of wheat, the Canadian government has prohibited the importation of barberry species (MacLatchy, 1996). Japanese barberry (Berberis thunbergii DC.) is an ornamental shrub appreciated for its hardiness and attractiveness but falls under the Canadian government prohibition of importation and domestic movement of barberry species in Canada.

Received for publication 4 Dec. 2006. Accepted for publication $26 \mathrm{Feb} .2007$.

We thank A.S. Sahota and C. Masters for maintaining the reference Japanese barberry plants, and A.S. Sahota for providing morphologic identification and putative off-type samples. A special thanks to R. Ormrod and the CFIA inspection staff for providing samples for the validation. We are grateful to L. DeVerno, C. Dollard, D. James, and $\mathrm{S}$. Nadin-Davis for reviewing the manuscript.

${ }^{1}$ To whom reprint requests should be addressed; e-mail cotemj@inspection.gc.ca
Because Japanese barberry is considered generally immune to rust (Melander and Craigie, 1927), the Canadian government has developed a program permitting the importation, multiplication, and movement within Canada of only approved resistant cultivars of Japanese barberry (CFIA, 2002). Accurate identification of Japanese barberry cultivars, especially for the distinction of the 11 approved cultivars, is essential for the success of the program. In the application of the program, Japanese barberry cultivars are identified by government officials primarily based on morphology. However, variation in growth conditions or importation in a dormant state may influence or limit the number of morphologic characters in such a way that accurate identification becomes difficult.

DNA fingerprinting techniques have been proven to be reliable for cultivar identification because the markers are not influenced by environmental factors, life stage, or type of plant tissue analyzed. The choice of a fingerprinting method for cultivar identification depends mainly on the application and the time and cost related to method development. Semiarbitrary-primed polymerase chain reaction (PCR) methods were assessed for the selection of a DNA fingerprinting technique for the following reasons. 1) No sequencing data are required for their development; therefore, the time involved for the development of the method is shorter; this is especially useful for an ornamental crop that has not yet been extensively studied at the molecular level. 2) These fingerprinting methods are reasonably reproducible and generate a high number of polymorphisms per primer set, therefore allowing cultivar identification in a few PCR reactions. The amplified fragment length polymorphism (AFLP) technique was selected as the method of choice for Japanese barberry cultivar verification because it has proven to be reproducible and to generate highly polymorphic patterns (Vos et al., 1995).

AFLP is based on the selective amplification of restriction-digested DNA fragments of the genome of interest through the ligation of adaptors composed of the restriction enzyme site and selective nucleotides (Vos et al., 1995). Recently, AFLP has been used for the cultivar identification of various crops, including celery (Apium graveolens L.) (Li and Quiros, 2000), mango (Mangifera indica L.) (Kashkush et al., 2001), strawberry [Fragaria $\times$ ananassa (Weston) Duchesne ex Rozier (pro sp.)] (Tyrka et al., 2002), apricot (Prunus armeniaca L.) (Geuna et al., 2003), and poinsettia (Euphorbia pulcherrima Willd. ex Klotzsch) (Parks and Moyer, 2004). In all of these studies, AFLP successfully and effectively differentiated cultivars, therefore allowing their identification. Furthermore, AFLP was used for the characterization of natural populations of Berberis species in Argentina, therefore demonstrating the applicability of the method for the Berberis genus (Bottini et al., 2002).

The main objective of this study was to use AFLP as a fingerprinting method for the identification of approved Japanese barberry cultivars. This was done by establishing a set of polymorphic AFLP bands used to score Japanese barberry samples submitted for cultivar verification. The established method was then verified using leaves or branches from Japanese barberry plants sampled in nurseries across Canada. Suspected mislabeled plant samples and samples from plants demonstrating unusual morphologic characters were tested as well. The AFLP method successfully confirmed the variety indicated on the label for both mature and dormant plants. Furthermore, the method allowed the identification of plants that were confirmed to be mislabeled by the exporter.

\section{Materials and Methods}

Plant material and DNA extraction. One to six plants representative of 22 cultivars of Japanese Barberry (Berberis thunbergii) were used to generate cultivar reference AFLP fingerprints. Two cultivars of Holly [Mahonia aquifolium (Pursh) Nutt.] were used as outgroup controls because the Mahonia genus is part of the same family as Japanese barberry: Berberidaceae (Table 1). All plant material representative of the 11 Japanese barberry cultivars approved for importation into Canada were collected from at least two sites. The plants from these sites were originally imported from the breeder and are maintained by the Canadian Food Inspection Agency as reference plants (Table 1). The 
Table 1. Japanese barberry and holly varieties used to generate reference amplified fragment length polymorphism patterns.

\begin{tabular}{|c|c|c|c|}
\hline Variety & No. of plants tested & Location & Year of plantation \\
\hline$\overline{\text { Auria Nana }}{ }^{z}$ & 4 & Saanichton $^{y}$ & 2002 \\
\hline Auria Nana & 1 & Ottawa $^{\mathrm{x}}$, site 1 & 1999 \\
\hline Bailtwo Burgundy carousel & 2 & Ottawa, site 2 & 1997 \\
\hline Monomb Cherry Bomb & 3 & Saanichton & 2002 \\
\hline Monomb Cherry Bomb & 6 & Ottawa, site 1 & 1999 \\
\hline Compact Oregon Grape Holly & 1 & Ottawa, site 2 & 2002 \\
\hline Concorde & 4 & Saanichton & 2002 \\
\hline Concorde & 5 & Ottawa, site 1 & 1999 \\
\hline Crimson Pygmy & 2 & Ottawa, site 2 & 1997 \\
\hline Tara Emerald Carousel & 2 & Ottawa, site 2 & 1997 \\
\hline Tara Emerald Carousel & 5 & Ottawa, site 1 & 1999 \\
\hline Golden Carousel & 2 & Ottawa, site 2 & 1997 \\
\hline Golden & 2 & Ottawa, site 1 & 1997 \\
\hline Monlers Golden Nugget & 5 & Ottawa, site 1 & 1999 \\
\hline Monlers Golden Nugget & 3 & Saanichton & 2002 \\
\hline Bailgreen Jade Carousel & 1 & Ottawa, site 2 & 1997 \\
\hline Bailgreen Jade Carousel & 5 & Ottawa, site 1 & 1999 \\
\hline Kobold & 2 & Ottawa, site 2 & 1997 \\
\hline Mentor & 2 & Ottawa, site 2 & 1997 \\
\hline Oregon Grape Holly & 1 & Ottawa, site 2 & 1997 \\
\hline Red Leaf & 2 & Ottawa, site 2 & 1997 \\
\hline Rose Glow & 3 & Saanichton & 2002 \\
\hline Rose Glow & 5 & Ottawa, site 1 & 1999 \\
\hline Gentry Royal Burgundy & 4 & Ottawa, site 1 & 1999 \\
\hline Gentry Royal Burgundy & 3 & Saanichton & 2002 \\
\hline Royal Cloak & 4 & Saanichton & 2002 \\
\hline Royal Cloak & 5 & Ottawa, site 1 & 1999 \\
\hline Bailone Ruby Carousel & 1 & Ottawa, site 2 & 1997 \\
\hline Bailone Ruby Carousel & 5 & Ottawa, site 1 & 1999 \\
\hline Sparkle & 2 & Ottawa, site 2 & 1997 \\
\hline Sparkle Japanese & 2 & Ottawa, site 2 & 1997 \\
\hline Monry Sunsation & 5 & Ottawa, site 1 & 1999 \\
\hline Monry Sunsation & 3 & Saanichton & 2002 \\
\hline Thornless & 2 & Ottawa, site 2 & 1997 \\
\hline William Penn & 2 & Ottawa, site 2 & 1997 \\
\hline
\end{tabular}

${ }^{\mathrm{z}}$ Variety names in bold are reference plant cultivars approved for importation in Canada.

y Maintained by C. Masters, Canadian Food Inspection Agency, Saanichton, Sidney Laboratory, British Columbia, Canada.

${ }^{x}$ Maintained by A.S. Sahota, Ontario Plant Laboratories-Seed Science, Canadian Food Inspection Agency, Ottawa, Ontario, Canada.

AFLP method was validated using a total of 50 samples representative of Japanese barberry cultivars collected across Canada and submitted by the Canadian Food Inspection Agency (CFIA) officers (Table 2). Among these samples, there was a representative of a 23rd Japanese barberry cultivar, 'Sheridan Red'. Six requests for cultivar verification after morphologic examination were also included to expand the analysis.

DNA was extracted mainly from leaf tissue and occasionally from branch tissue using the protocol as outlined by Doyle and Doyle (1990). When branch tissue was used for DNA extraction, the bark was removed before grinding. Serial dilutions of all DNA extracts were quantified on $1.5 \%$ agarose gel electrophoresis by comparing their intensity relative with the Low DNA Mass Ladder (Invitrogen Life Technologies, Burlington, Ontario, Canada) band of the most comparable size. The dilutions allowed more accuracy in the quantification because bands that were not saturated with dye were used for intensity comparison.

Amplified fragment length polymorphism procedure. AFLP was carried out using the AFLP Analysis System (Invitrogen Life Technologies) according to the two-step amplification protocol outlined by the manufacturer with the following modifications: 5 units of Taq DNA polymerase I were used per preamplification (step 1) reaction instead of one unit and the selective amplification (step 2) was performed on 1:10 dilution of the template from preamplification instead of 1:50. Primers described in Table 3 were used and two primer sets were selected to generate AFLP patterns to differentiate Japanese barberry cultivars, EcoRI-ACC + MseI-CAC and EcoRI-AGG with MseI-CAT. EcoRI primers were labeled with IRDye700 (LICOR Biosciences, Lincoln, Neb.) and MseI primers were purchased from Invitrogen Life Technologies. AFLP products are separated on $8 \%$ LongRanger (BioWhittaker Molecular Applications, Rockland, Maine), $7 \mathrm{~m}$ urea set on a NEN Global IR 4200 DNA analyser system (LI-COR Biosciences), and ran in $0.8 \times$ TBE.

Amplified fragment length polymorphism data collection and analysis. AFLP band scoring was performed using Saga Generation 2 software (LI-COR Biosciences). A predetermined set of polymorphic bands were scored as present $(+)$ or absent $(-)$. Data generated from each run were exported to a database in which all the AFLP fingerprints were collected for comparison and identification purposes. The data were converted to a presence (1) or absence (0) format for similarity analysis using the Jaccard similarity index. The similarity index of Jaccard was constructed and analyzed using the numeric Taxonomy and Multivariate Analysis System (NTSYS-pc version 2.2; F. James Rohlf, University of New York). In a first step, the Jaccard similarity index was determined using the SIMQUAL program, which computes a variety of similarity and dissimilarity coefficients for qualitative data. The resulting dendrogram was then generated using the Unweighted Pair Group Arithmetic Average Method-UPGMA one of the SAHN sequential, agglomerative, hierarchical, and nested clustering programs.

\section{Results}

Selection of amplified fragment length polymorphism primer sets and cultivar polymorphic bands. Sixty-four AFLP primer set combinations (Table 3 ) were tested using a representative of each of the 11 approved Japanese barberry cultivars (Table 1). Four primer sets, E-ACC + M-CAC, E-AGG + $\mathrm{M}-\mathrm{CAT}, \mathrm{E}-\mathrm{ACA}+\mathrm{M}-\mathrm{CAC}$, and E-ACA + M-CTA, were selected for further testing because they were presenting a significant number (greater than 15) of polymorphic bands relative to the other primer sets and were not producing smears. The selected primer sets were then tested using DNA samples representative of all cultivars cited in Table 1. Primer sets E-ACC + M-CAC and E-AGG + M-CAT were further selected because they were the most discriminative; they could differentiate most cultivars tested to the same extent as when using all four sets. The AFLP polymorphic bands that would be used to score Japanese barberry cultivars were selected preferentially if they were present in more than one cultivar but not in all cultivars. Following this criteria, 33 reference polymorphic bands ranging in size from 333 to 104 bp were selected from the AFLP patterns produced by both primer sets. The presence/absence of the selected reference bands relative to each approved cultivar is shown in Table 4 . The system of 33 selected AFLP bands produced by two primer sets for the identification of Japanese barberry cultivars was tested using DNA extracted from as many plants as possible for each approved cultivar (Table 1). Some AFLP bands showed polymorphism within a cultivar; for example, for the 'Rose Glow' cultivar, band 156 $(\mathrm{E}-\mathrm{ACC}+\mathrm{M}-\mathrm{CAC})$ was sometimes absent and sometimes present (Table 4; Fig. 1). A similar situation was observed for band 327 (E-AGG + M-CAT) for the cultivar Royal Burgundy (Table 4). AFLP patterns were also collected for nonapproved Japanese barberry and two Holly cultivars (Table 1). AFLP patterns generated from all reference plants were recorded in a database for future use as a reference for cultivar verification or identification. 
Table 2. Japanese barberry cultivars submitted for method validation or cultivar verification using amplified fragment length polymorphism.

\begin{tabular}{lccc}
\hline $\begin{array}{l}\text { Cultivars submitted } \\
\text { for validation }\end{array}$ & $\begin{array}{c}\text { Total no. of } \\
\text { submission }\end{array}$ & $\begin{array}{c}\text { Cultivar label } \\
\text { confirmed }\end{array}$ & No result \\
\hline Auria Nana & 3 & 3 & 1 \\
Monomb Cherry Bomb & 3 & 2 & $1^{z}$ \\
Concorde & 3 & 3 & \\
Tara Emerald Carousel & $2^{z}$ & 1 & 1 \\
Monlers Golden Nugget & 3 & 1 & \\
Bailgreen Jade Carousel & 1 & 16 & \\
Rose Glow & 17 & 4 & \\
Gentry Royal Burgundy & 4 & 3 & Cultivar \\
Royal Cloak & 3 & 2 & mislabeled \\
Bailone Ruby Carousel & 2 & 3 & 1 \\
Monry Sunsation & 3 & cultivar label \\
Japanese barberry cultivar & Total no. of & 1 & 1 \\
submitted for verification & submissions & 1 & \\
Concorde & 1 & 1 & \\
Tara Emerald Carousel & 1 & 1 & \\
Rose Glow & 2 & & \\
Bailone Ruby Carousel & $2^{z}$ & &
\end{tabular}

${ }^{2}$ DNA was extracted from branch tissue for one sample.

Table 3. Amplified fragment length polymorphism primer sets assessed for Japanese barberry cultivar identification.

\begin{tabular}{lc}
\hline EcoRI & MseI \\
5'-GATGAGTCCTGAGTAA-NNN-3' $^{\prime}$ & 5'-GACTGCGTACCAATTC-NNN-3' $^{\prime}$ \\
\hline E'-AAC $^{\text {z }}$ & M $^{\text {z-CAA }}{ }^{\text {y }}$ \\
E-AAG & M-CAC \\
E-ACA & M-CAG \\
E-ACC & M-CAT \\
E-ACG & M-CTA \\
E-ACT & M-CTC \\
E-AGC & M-CTG \\
E-AGG & M-CTT \\
\hline
\end{tabular}

${ }^{\mathrm{z}}$ Corresponds to the nucleotide sequence above each column.

"Nucleotides corresponding to "NNN" above each column.

Analysis of the genetic relationship between Japanese barberry cultivars. The genetic relationship between representative plants of all of the reference Japanese barberry cultivars described in Table 1 was analyzed using the selected AFLP polymorphic bands generated for the Japanese barberry cultivar verification method (Fig. 2). Cultivars segregating together but still showing differences in AFLP patterns were used to establish a range of matching polymorphic bands used as criteria of acceptance for cultivar verification. Based on variations observed between and within approved Japanese barberry cultivars, it was determined that a sample would be of the same cultivar as the reference if it matched 31 or more of the 33 set polymorphic bands. However, if a sample shared less than 28 of the 33 polymorphic bands, the sample would be a different cultivar than the reference. There were two pairs of cultivars that could not be distinguished because they produced identical AFLP patterns for all selected primer sets used, 'Cherry Bomb' from 'Crimson Pigmy' and 'Aurea Nana' from 'Golden' (Fig. 2). Furthermore, 64 combinations of AFLP primer sets (Table 3) were tested to find a polymorphism between 'Cherry Bomb' and 'Crimson Pigmy' but did not reveal any differences between the two cultivars (data not shown).
Validation of the amplified fragment length polymorphism Japanese barberry cultivar verification method. Branches of Japanese barberry plants sampled in nurseries across Canada were used to validate the AFLP Japanese barberry cultivar verification method. The cultivar indicated on the label and the number of plants submitted per cultivar is listed in Table 2. DNA was extracted in duplicate for all samples and most were processed from leaves. There were two samples for which DNA was extracted from branches (Table 2). Overall, three samples, two from leaves and one from branches, failed to produce a recognizable AFLP pattern probably as a result of the poor quality of the DNA extracted. Results for 41 of the samples submitted for validation corresponded to the Japanese barberry cultivar indicated on the label.

Analysis of Japanese barberry cultivar samples submitted for verification. A total of six Japanese barberry samples were sent by the CFIA officers for cultivar verification after morphologic evaluation (Table 2). The AFLP pattern of four samples corresponded to the pattern expected for the cultivar indicated on the label. However, two of the samples submitted, samples 03 and 58, produced an AFLP pattern that did not correspond to the cultivar name on the label. The AFLP pattern of the sample labeled 'Ruby
Carousel' (sample 03) did not correspond to the reference 'Ruby Carousel' pattern, matching the reference 'Ruby Carousel' at only 18 of 33 of the polymorphic bands set for this cultivar (Table 4; Fig. 1). The sample instead showed an AFLP pattern identical (33 of 33) to the pattern of the nonapproved cultivar 'Sheridan Red' (Table 4; Fig. 1). The AFLP pattern generated from sample 58 labeled 'Rose Glow' did not correspond to the pattern of the reference 'Rose Glow' because it matched the reference 'Rose Glow' on only 20 of the 33 polymorphic bands (Table 4; Fig. 1). Instead, sample 58 had an identical pattern as the references 'Cherry Bomb' and 'Crimson Pigmy' (Table 4; Fig. 1).

\section{Discussion}

Differentiation of Japanese barberry cultivars using amplified fragment length polymorphism. AFLP successfully differentiated all 11 approved Japanese barberry cultivars, thereby providing a means for the authorities to verify the identity of suspect imported plants or dormant material difficult to identify morphologically at the cultivar level. Similar studies of cultivar differentiation were done on gooseberry (Ribes grossularia subgenus Grossularia) (Lanham and Brennan, 1999) and olive (Olea europaea L.) (Montemurro et al., 2005) in which AFLP was compared with other techniques such as single sequence repeat (SSR) and intersimple sequence repeat or anchored microsatellites. In those studies, AFLP was able to differentiate all cultivars or genotypes tested and was found to be one of the most discriminative methods available. Furthermore, this technique had an added advantage in that it required only one primer set to differentiate most cultivars tested, whereas other methods (such as SSRs) required several sets to achieve the same level of discrimination.

In Figure 2, the same Japanese barberry cultivars from two field plots cosegregated confirming the AFLP genotype of each reference plant for these cultivars. There were two pairs of Japanese barberry cultivars that could not be distinguished from each other, 'Cherry Bomb' from 'Crimson Pigmy' and 'Aurea Nana' from 'Golden' (Fig. 2). 'Cherry Bomb' is a sport of 'Crimson Pigmy', the main morphologic difference being 'Cherry Bomb' grows taller (www.aphis. usda.gov/ppq/barberry/berberis.html). Sport mutations are difficult to differentiate genetically from the original cultivar as was shown for poinsettia (Parks and Moyer, 2004). Furthermore, a study on cultivar identification in peach (Prunus persica L. Batsch) involving 212 peach and nectarine commercial cultivars demonstrated that when sport duplications were removed, there was an increase in the number of cultivars differentiated (Arús et al., 2003). Because AFLP represents a selection of the variation throughout the genome and in a random fashion, it is likely not encompassing the genetic variation 


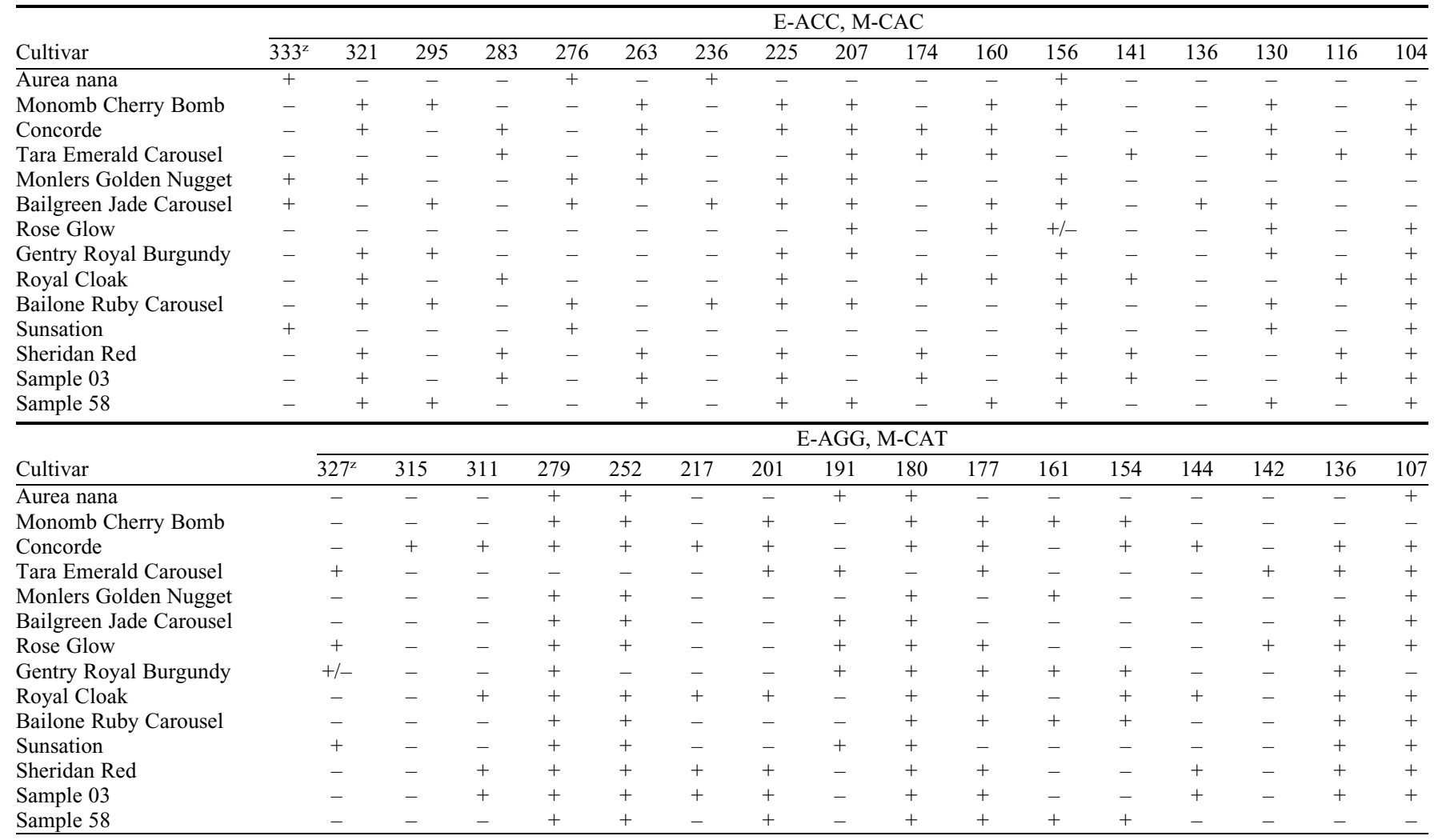

${ }^{\mathrm{z} A m p l i f i e d ~ f r a g m e n t ~ l e n g t h ~ p o l y m o r p h i s m ~ p o l y m o r p h i c ~ b a n d ~ n a m e d ~ a c c o r d i n g ~ t o ~ t h e ~ c o r r e s p o n d i n g ~ n u m b e r ~ o f ~ b p s ~ e s t i m a t e d ~ b y ~ S A G A ~ G e n e r a t i o n ~} 2$ software (LI-COR Biosciences).

resulting in a single morphologic trait. It is possible that the same situation applies for 'Golden' and 'Aurea Nana' cultivars. 'Golden' and 'Aurea' are taller than 'Auria Nana', and it might be that one of the two cultivars is the sport mutation of the other one. An efficient solution for the differentiation of sport mutants would be the development of trait-specific markers.

Reproducibility and robustness of amplified fragment length polymorphism as a cultivar verification method. Generally, the technical variation of AFLP patterns depends on the completion of the restriction digestion initially performed on the extracted DNA. Variation in the quality of the DNA extracted may prevent complete digestion and hence availability of restriction fragments selected to be amplified, thereby changing the resulting AFLP pattern. The material received for Japanese barberry cultivar verification is generally fresh and enough tissue is available for extraction, increasing the probability of recovering high-quality DNA. Variation in the quantity of DNA may also be another factor because an excess of DNA may also prevent complete digestion. However, by using 200 to $250 \mathrm{ng}$ of DNA, any slight variation that could occur by quantification using a gel-based method was not significant enough to put the amount of DNA used out of the range suggested by the manufacturer (100 to $500 \mathrm{ng}$ ), thus making the method more robust. DNA extracted from either leaves or branches produced similar patterns.
All through this study, samples that failed to produce a recognizable AFLP pattern were generally amplified from plant material that was compromised by poor growth, senescence, or poor shipping conditions.

AFLP patterns obtained from Japanese barberry cultivars were generally very uniform and reproducible. The fact that Japanese barberry is generally vegetatively propagated does limit the genetic variation within cultivars. Some of the observed variations were seen only once and believed to be the result of an incomplete digestion of the extracted DNA. However, these were easily identified because the DNA extraction was performed in duplicate. This practice adds further value to the procedure by increasing the accuracy and confidence in the AFLP pattern obtained.

However, some variations were observed for several individual plants leading to the conclusion of natural genetic variation within the cultivar. It is possible, and even expected, to observe some natural variations within cultivars. Variations of the AFLP pattern for the two primer sets within the same cultivar were not more than at two positions. This allowed the setting of a minimum number of matching AFLP bands: 31 of a total possible of 33 within a cultivar. Japanese barberry cultivar 'Red Leaf' was the exception because both plants reproducibly matched each other for 30 of the possible 33 AFLP bands. We believe that 'Red Leaf' is also named 'Atropurpurea' and therefore is the parent of several red Japanese barberry cultivars such as 'Royal Cloak', 'Concorde', 'Rose Glow', 'Burgundy Carousel', 'Royal Burgundy', 'Crimson Pygmy', 'Cherry Bomb', and 'Ruby Carousel'. The selection pressure might have been different for this particular cultivar and with time, more genetic variations would have been generated among individuals. More representative plants of the cultivar 'Atropurpurea' will have to be genotyped to properly assess its genetic variability. 'Red Leaf' is not an approved cultivar and shares only 27 or 28 of the set AFLP bands with the closest related approved cultivar, 'Cherry Bomb'. In addition, the similarity between the cultivars 'Kobold' and 'Cherry Bomb'/ 'Crimson Pigmy' is 30 on 33. This supports the choice of using 31 of 33 as the minimum number of shared AFLP bands for varietal identification.

Application of the Japanese barberry cultivar verification method. The validation results of the AFLP method as a Japanese barberry cultivar verification successfully confirmed that the method was ready to be used for routine diagnostics. Therefore, samples that were morphologically difficult to identify by the CFIA staff were sent for molecular cultivar verification after partial morphologic analysis. Two of the submitted samples were mislabeled by the exporter and furthermore, one (sample 03) produced AFLP patterns that did not correspond to any of the approved Japanese barberry cultivars 


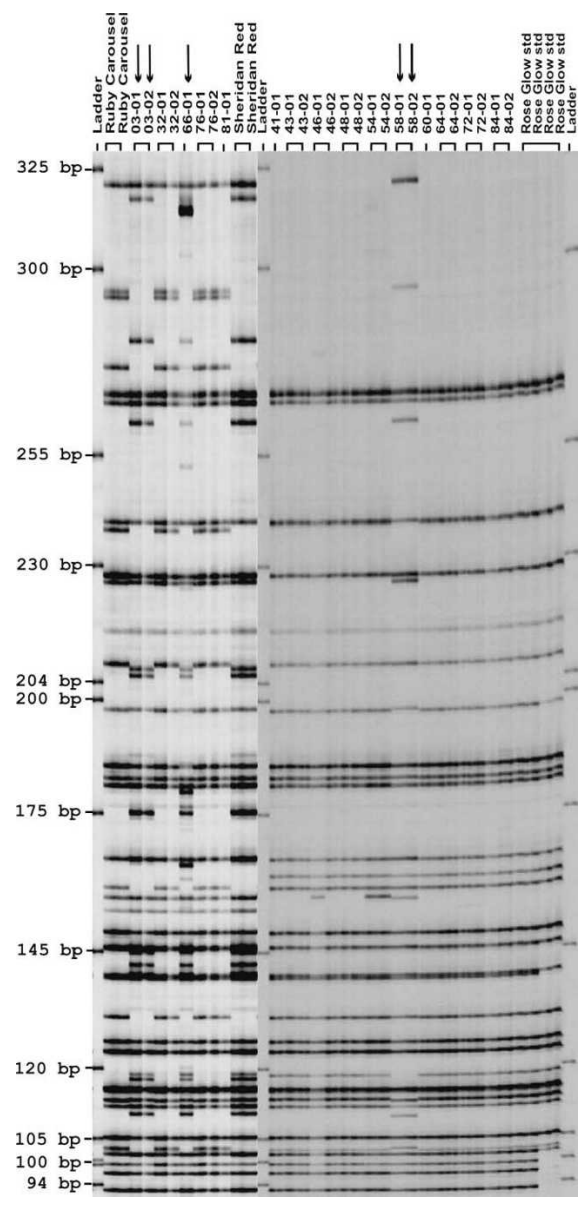

Fig. 1. Amplified fragment length polymorphism patterns generated using primer sets E-ACC, M-CAC on 15 Japanese barberry samples sent for validation and cultivar verification. Each lane represents a single DNA extraction because samples are done in duplicate. The reference cultivars are identified by their name. Samples 03, 32, 66, 76, and 81 are putative 'Ruby Carousel' cultivars and samples 41,43 , $46,48,54,58,60,64,72$, and 84 are putative 'Rose Glow' cultivars. Arrow points to mislabeled samples. Sample 66 corresponds to another submission of sample 03 . The sizes of the DNA bands from the 50-350 ladder (LICOR Biosciences) are indicated on the left side.

(Table 4) but matched instead the nonapproved 'Sheridan Red' (Fig. 2) requiring action from the government authority for this particular shipment. The other sample that was mislabeled by the exporter matched an approved Japanese barberry genotype, 'Cherry Bomb', but also its cosegregating parent 'Crimson Pigmy' (Fig. 2), which is not approved for entry into the country.

A Japanese barberry cultivar verification method was established using AFLP as a complementary identification method for samples morphologically difficult to verify to be true-to-type. Although it was not possible to differentiate sport mutants, the method was discriminative enough to differentiate between the 11 approved cultivars permitted entry into Canada. The application of the cul-

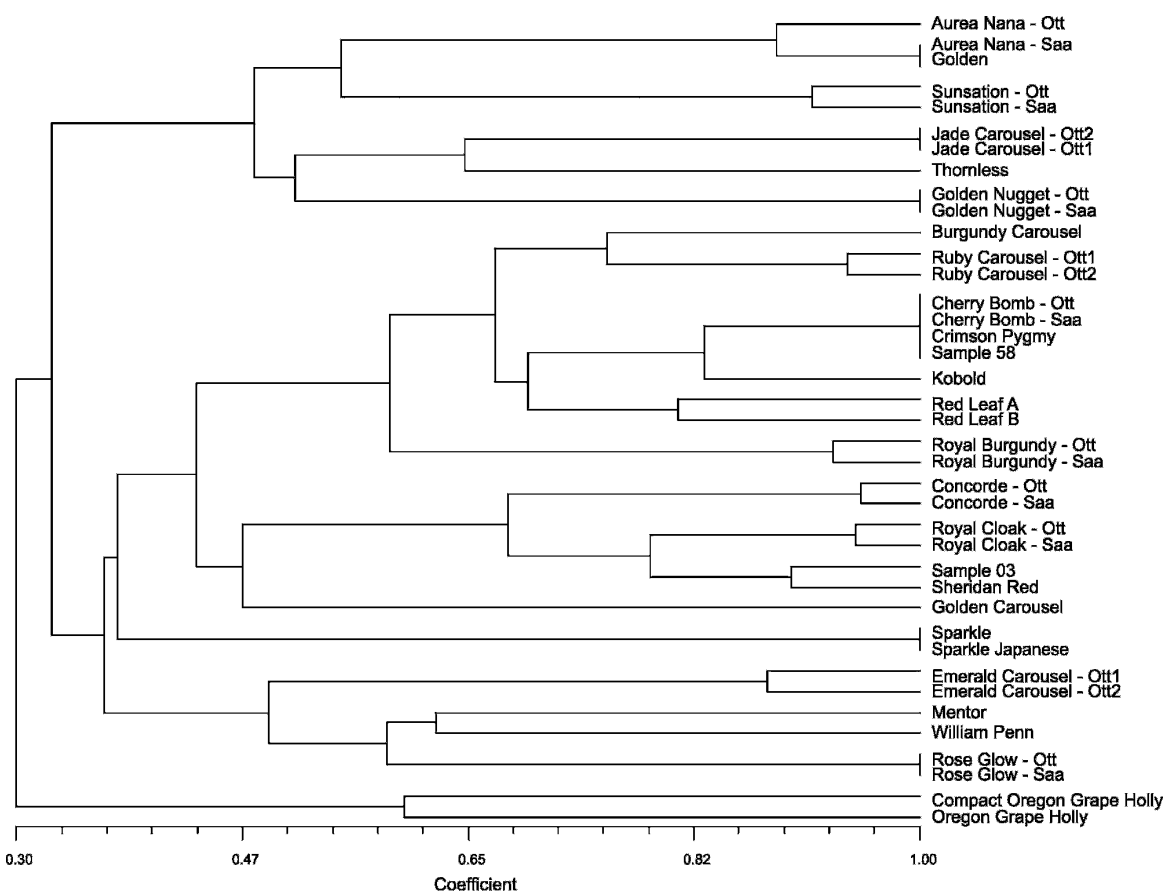

Fig. 2. UPGMA dendrogram obtained for reference samples of Japanese barberry cultivars. The Jaccard's similarity coefficient is indicated at the base of the dendrogram. The reference cultivar samples and their sources are listed in Table 1. Saa corresponds to Saanichton, Ott and Ott1 correspond to Ottawa, site 1 , and Ott2 to Ottawa, site 2. In addition to the cultivars listed on Table 1, 'Sheridan Red' and the mislabeled sample 03 and 58 (Tables 2 and 4).

tivar verification method allowed the detection and identification of two samples that were mislabeled by the exporter. Furthermore, the AFLP analysis method established for Japanese barberry cultivar verification is discriminative enough to allow for eventual inclusion of other approved cultivars with minimal technical modification.

\section{Literature Cited}

Arús, P., M.J. Aranzana, and J. Carbó. 2003. SSR and AFLP markers for germplasm evaluation and cultivar identification in peach. Acta Hort. 606:34-40.

Bottini, M.C.J., A. De Bustos, N. Jouve, and L. Poggio. 2002. AFLP characterization of natural populations of Berberis (Berberidaceae) in Patagonia, Argentina. Plant Syst. Evol. 231: 133-142.

CFIA. 2002. Plant protection import and domestic movement requirements for barberry (Berberis, Mahoberberis, Mahonia). Plant Health and Production Division. Canadian Food Inspection Agency D 01-04:1-24.

Clark, R.V., W.L. Seaman, and J.W. Martens. 1986. Puccinia graminis on barberry and oats in eastern Ontario from 1968 to 1983. Can. J. Plant Pathol. 8:193-200.

Doyle, J.J. and J.L. Doyle. (1990). Isolation of plant DNA from fresh tissue. Focus 12\#1.

Geuna, F., M. Toschi, and D. Bassi. 2003. The use of AFLP markers for cultivar identification in apricot. Plant Breed. 122:526-531.

Kashkush, K., F. Jinggui, E. Tomer, J. Hillel, and U. Lavi. 2001. Cultivar identification and genetic map of mango (Mangifera indica). Euphytica 122:129-136.

Lanham, P.G. and R.M. Brennan. 1999. Genetic characterization of gooseberry (Ribes grossu- laria subgenus Grossularia) germplasm using RAPD, ISSR and AFLP markers. J. Hort. Sci. Biotechnol. 74:361-366.

Li, G. and C.F. Quiros. 2000. Use of amplified fragment length polymorphism markers for celery cultivar identification. HortScience 35:726-728.

MacLatchy, I.A. (1996). Berberis thunbergii (Japanese barberry) as a potential obstacle to the control of Puccinia graminis (Stem rust of wheat). Plant Health Risk Assessment Unit, Agriculture and Agri-Food Canada 3510-31B2.

Melander, L.W. and J.H. Craigie. 1927. Nature of resistance of Berberis spp. to Puccinia graminis. Phytopathology 17:95-114.

Montemurro, C., R. Simeone, A. Pasqualone, E. Ferrara, and A. Blanco. 2005. Genetic relationships and cultivar identification among 112 olive accessions using AFLP and SSR markers. J. Hort. Sci. Biotechnol. 80:105110.

Parks, E.J. and J.W. Moyer. 2004. Evaluation of AFLP in poinsettia: Polymorphism selection, analysis, and cultivar identification. J. Amer. Soc. Hort. Sci. 129:863-869.

Pierce, R. (1981). Stemming stem rust. Agricultural Research, March:7-8.

Roelfs, A.P. 1982. Effects of barberry eradication on stem rust in the United States. Plant Dis. 66:177-181.

Tyrka, M., P. Dziadczyk, and J.A. Hortyński. 2002. Simplified AFLP procedure as a tool for identification of strawberry cultivars and advanced breeding lines. Euphytica 125:273280.

Vos, P., R. Hogers, M. Bleeker, M. Reijans, T. van de Lee, M. Hornes, A. Frijters, J. Pot, J. Peleman, M. Kuiper, and M. Zabeau. 1995. AFLP; a new technique for DNA fingerprinting. Nucleic Acids Res. 23:4407-4414. 